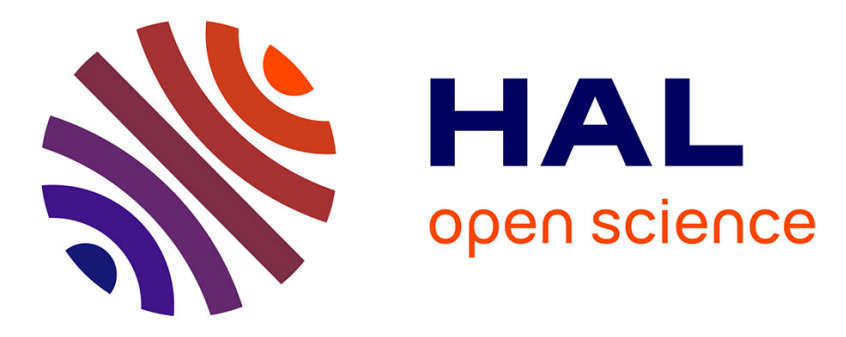

\title{
Cause-effect relationship among morphological adaptations, growth, and gas exchange response of pedunculate oak seedlings to waterlogging
}

Fabienne Tatin-Froux, Nicolas Capelli, Julien Parelle

\section{- To cite this version:}

Fabienne Tatin-Froux, Nicolas Capelli, Julien Parelle. Cause-effect relationship among morphological adaptations, growth, and gas exchange response of pedunculate oak seedlings to waterlogging. Annals of Forest Science, 2014, 71 (3), pp.363-369. 10.1007/s13595-013-0340-6 . hal-01101530

\author{
HAL Id: hal-01101530 \\ https://hal.science/hal-01101530
}

Submitted on 8 Jan 2015

HAL is a multi-disciplinary open access archive for the deposit and dissemination of scientific research documents, whether they are published or not. The documents may come from teaching and research institutions in France or abroad, or from public or private research centers.

$$
\text { Copyright }
$$

L'archive ouverte pluridisciplinaire HAL, est destinée au dépôt et à la diffusion de documents scientifiques de niveau recherche, publiés ou non, émanant des établissements d'enseignement et de recherche français ou étrangers, des laboratoires publics ou privés. 


\title{
Cause-effect relationship among morphological adaptations, growth, and gas exchange response of pedunculate oak seedlings to waterlogging
}

\author{
Fabienne Tatin-Froux • Nicolas Capelli • Julien Parelle
}

Received: 16 May 2013 / Accepted: 4 October 2013 /Published online: 8 November 2013

(C) INRA and Springer-Verlag France 2013

\begin{abstract}
- Context In response to waterlogging, pedunculate oak is known to develop adventitious roots and hypertrophied lenticels. However, to date, a link between these adaptations and the ability to maintain net $\mathrm{CO}_{2}$ assimilation rates and growth has not been demonstrated.

- Aims The aim of this study was to explore the cause-effect relationship between the ability to form morphological adaptations (hypertrophied lenticels and adventitious roots) and the capacity to maintain high assimilation rate and growth.

- Methods The occurrence of morphological adaptations and the parameters of photosynthesis were monitored over 20 days of waterlogging in 5-week-old pedunculate oak seedlings presenting similar morphological development.

- Results Based on the development or not of morphological adaptations, the following three categories of responses were identified: development of hypertrophied lenticels and adventitious roots, development of hypertrophied lenticels alone, and the lack of development of adaptive structures. These categories, ranked in the order given, corresponded to decreasing levels of initial net $\mathrm{CO}_{2}$ assimilation rate growth and photosynthesis parameters observed during waterlogging.

- Conclusion We observed a two-way cause-effect relationship between the capacity to form adaptive structures and the assimilation rate. Indeed, the initial assimilation rate determined the
\end{abstract}

\section{Handling Editor: Erwin Dreyer}

Contribution of the co-authors Fabienne Tatin-Froux and Julien Parelle contributed to the entire study, and Nicolas Capelli contributed to writing the manuscript

F. Tatin-Froux $(\bowtie) \cdot$ N. Capelli $\cdot$ J. Parelle

UMR Chrono-Environnement UFC/CNRS 6249 USC INRA

Université de Franche-Comté, Place Leclerc,

25030 Besançon cedex, France

e-mail: fabienne.tatin-froux@univ-fcomte.fr occurrence of hypertrophied lenticels and growth during stress, and then the development of morphological adaptations enhanced the ability to maintain assimilation levels during the stress.

Keywords Quercus robur · Waterlogging · Hypertrophied lenticels $\cdot$ Adventitious root $\cdot$ Photosynthesis

\section{Introduction}

Waterlogging is characterized by excess water in the soil leading to the partial (hypoxia) or total (anoxia) deficiency of soil oxygen. These soil conditions cause oxygen deprivation to the root system of plants. The effects of this type of stress have been described, including the identification of physiological dysfunctions in large numbers of species (for reviews, see Kozlowski 1997; Kreuzwieser et al. 2004), leading to a rapid decrease in carbon assimilation and ultimately growth inhibition and death. Whereas a number of studies have demonstrated evidence of hydraulic effects leading to stomatal closure (Pezeshki et al. 1996; Mielke et al. 2003), current opinion maintains that the assimilation rate in temperate tree species is limited mainly by biochemical effects (Dreyer 1994; Gravatt and Kirby 1998; Copolovici and Niinemets 2010; Ferner et al. 2012). The majority of these studies demonstrated that tree species can be classified according to their tolerance level, defined by the limitation of photosynthesis, which could be caused by problems with phloem unloading in oxygen-deficient root systems, resulting in lower exportation from the leaves (Ferner et al. 2012).

Woody plants adapted to waterlogging conditions develop morphological adaptations, such as adventitious roots, hypertrophied lenticels, and root cortical lacunas, which could improve the transfer of oxygen to the roots. The formation of 
hypertrophied lenticels on submerged stems and on the main root has been described in a large variety of woody plant species (reviewed in Kozlowski 1997). In several species, such as the common alder (Dittert et al. 2006), the role of hypertrophied lenticels in $\mathrm{O}_{2}$ transport to the roots has been demonstrated. A small number of studies have demonstrated that the development of hypertrophied lenticels counterbalances the effects of waterlogging on the physiology of leaves. Larson et al. (1991) observed hypertrophied lenticels on mango trees that survived waterlogging, but not on the trees that died. It is also possible that the production of adventitious roots improved the water status of the trees. Indeed, in Fraxinus pennsylvanica subjected to a long period of waterlogging, a decrease in stomatal conductance followed by a high coordination between stomatal reopening and the formation of adventitious roots was observed (Sena Gomes and Kozlowski 1980; Tang and Kozlowski 1984). The restoration of root hydraulic conductance might explain the enhancement of the water status of these plants (Calvo-Polanco et al. 2012); however, the effect on growth and assimilation was not investigated.

Pedunculate oak (Quercus robur L.) is a European broadleaved tree species that can grow in temporarily waterlogged soils. This tolerance was observed as well for adult trees submitted to spring water-logging events (Lévy et al. 1999) as for seedlings under controlled conditions (Wagner and Dreyer 1997). Morphological adaptations, such as the development of adventitious roots (Parelle et al. 2006), hypertrophied lenticels (Parelle et al. 2007), and root cortex lacuna (Folzer et al. 2006; Parent et al. 2011) have been described in this species when the trees are subjected to waterlogging. The ability to develop these morphological adaptations enables the pedunculate oak to survive under waterlogged conditions, which may give this tree an advantage over other European woody species (Dreyer 1994). In spite of this potential ability to tolerate waterlogging, a large diversity of phenotypes, which are able or unable to develop morphological adaptations, have been observed in pedunculate oak seedlings subjected to this stress. For example, in a previous greenhouse study of pedunculate and sessile oak seedlings, the seedlings that died under waterlogging conditions were those that developed smaller numbers of hypertrophied lenticels (the association of seedling death with the ability to form adventitious roots was less evident, Parelle et al. 2007). Currently, at the intra-specific diversity level and regarding the ecophysiological process, little is known about the relationship between the development of adventitious roots or hypertrophied lenticels and carbon assimilation. More precisely, studies did not clearly discriminate whether the capacity to maintain assimilation rate and open stomata during water-logging is due to morphological adaptations, or if the assimilation capacity determines the development of adaptive structures.
In order to improve the understanding of this cause-effect relationship, we investigated the association of the formation of hypertrophied lenticels and adventitious roots with the evolution of the carbon assimilation rate during waterlogging. To identify seedlings that were able or not able to form these morphological adaptations, we monitored (using nondestructive methods) the appearance of these underground morphological changes in pots in which the upper portion of the soil was replaced with water. The experiment was performed during the formation of the second flush growth, to record the effect on the stem increment. To separate the initial photosynthetic capacities from the response to the stress, the assimilation rate was measured on the day preceding the stress and was monitored regularly during waterlogging.

This experimental procedure enabled us to investigate the following hypotheses:

- The formation of adventitious roots and/or hypertrophied lenticels enhances carbon assimilation rate and growth during waterlogging.

- The ability of individual plants to form hypertrophied lenticels and/or adventitious roots and to maintain growth during waterlogging is determined by the initial net $\mathrm{CO}_{2}$ assimilation rate.

\section{Materials and methods}

\subsection{Plant material and growth conditions}

The pedunculate oak (Quercus robur L.) acorns were harvested below a single isolated mother tree in eastern France (Recologne, Doubs, $47^{\circ} 27^{\prime} 51 \mathrm{~N}, 5^{\circ} 82^{\prime} 68 \mathrm{E}$ ) and stored at $4{ }^{\circ} \mathrm{C}$ until use. The acorns were shelled, oxygenated overnight in running water, and left in vermiculite for 1 week to promote germination. Individual acorns were grown in 1.81 pots containing river sand for 5 weeks, corresponding to the full establishment of the first growth flush but before the appearance of the second growth flush. The height of the first growth flush was measured before the start of the waterlogging and again at the end of the experiment, to ensure the complete development of the first growth stage. The plants were grown in a controlled growth chamber with the environmental conditions set as follows: a $16 \mathrm{~h}$ photoperiod, a photosynthetically active radiation (PAR) of approximately $400 \mu \mathrm{mol} \mathrm{m} \mathrm{m}^{-2} \mathrm{~s}^{-1}$ at leaf level (provided by high pressure sodium lamps), an average temperature of approximately $21{ }^{\circ} \mathrm{C}$ (day)/18 ${ }^{\circ} \mathrm{C}$ (night), and a relative humidity of approximately $70 \%$. The plants were irrigated 4 times a day using a fertilizer solution containing complete nutritive elements $\left(0.5 \mathrm{ml} \mathrm{l}^{-1}\right.$, NPK 6/5/6, SEM, Germany) using an automated Ebband-Flow system. 
2.2 Experimental design and identification of seedlings with different levels of adaptive structures

At 2 days before the beginning of waterlogging, the first $2 \mathrm{~cm}$ of sand under the collar was removed carefully to avoid breaking the roots and to allow the non-destructive visualization of the appearance of the hypertrophied lenticels and adventitious roots. The waterlogging was achieved by immersing the 5-week-old seedlings up to the collar in a single water tank in the irrigation solution for 20 days. The water-table was maintained at exactly this level by adding water, and no fluctuation was observed. Our objective was to produce a wide range of stress responses (plant able or not able to form adventitious roots and hypertrophied lenticels); therefore, we chose to submit 29 seedlings to waterlogging, and six seedlings were maintained under control conditions. At 1 day before the waterlogging and again at days $7,9,14$, and 20, the pots containing each seedling were removed from the water tank, and the morphological adaptations in the $2 \mathrm{~cm}$ of the visible part of the tap root (where the sand was removed) were determined. The development of adventitious roots was recorded as the presence or absence of white plagiotropic roots. The development of hypertrophied lenticels was recorded as the presence or absence of white spots (phellems) on the bark of the main root. The experiment was terminated on day 20. There were no differences observed in the ability of the seedlings to form adventitious roots and/or hypertrophied lenticels between days 14 and 20 .

The data were analyzed based on the ability of the seedlings to develop or not develop adventitious roots and/or hypertrophied lenticels (termed morphological adaptations throughout the text) during the 20 days of waterlogging. In total, four categories were defined as follows: (1) waterlogged seedlings with hypertrophied lenticels and adventitious roots $(n=$ 12), (2) waterlogged seedlings with hypertrophied lenticels but without adventitious roots $(n=7)$, (3) waterlogged seedlings with neither hypertrophied lenticels nor adventitious roots $(n=$ $10)$, and (4) control seedlings ( $n=6)$. In this study, each seedling that formed adventitious roots also developed hypertrophied lenticels. Seedlings were selected to have similar initial morphology and development. We measured no significant differences among initial height (waterlogged seedlings with hypertrophied lenticels and adventitious roots: $13.1 \pm 1.0 \mathrm{~cm}$, with hypertrophied lenticels only: $13.5 \pm 1.3 \mathrm{~cm}$, without morphological adaptations: $14.9 \pm 1.0 \mathrm{~cm}$; control seedlings: $12.8 \pm$ $1.5 \mathrm{~cm}$ ), and among the number of leaves (waterlogged seedlings with hypertrophied lenticels and adventitious roots: $5.3 \pm$ 0.2 , with hypertrophied lenticels only: $5.3 \pm 0.5$, with no morphological adaptations: $5.6 \pm 0.2$; control seedlings: $5.2 \pm 0.2$ ).

\subsection{Physiological and growth measurements}

The level of hypoxia was determined in piezometric tubes placed in the sand near the roots with a light dissolved oxygen probe (LDO probe, HQ40d recorder, Hache-Lange, Loveland, CO, USA). During the first $22 \mathrm{~h}$ of waterlogging, the oxygen content decreased from saturation level to $0.2 \mathrm{mg} \mathrm{l}^{-1}$. One day before the waterlogging and again on days $0,1,2,5,8,13$, and 20 , the net carbon assimilation and stomatal conductance to water vapor were measured on a single attached mature fully expanded leaf from the first growth stage in each of the seedlings. The measurements were performed in the middle of the photoperiod, over a 90-minute period, using a portable exchange gas analyzer (LiCOR 6400, Li-Cor ${ }^{\circledR}$ Inc., Lincoln, NE, USA) equipped with the artificial light source 6400-02B RedBlue. The measurements were performed with the block temperature fixed at $21{ }^{\circ} \mathrm{C}$, a flow rate to the sample of $200 \mu \mathrm{mol} \mathrm{s}{ }^{-1}$, a photosynthetic photon flux density of $400 \mu \mathrm{mol} \mathrm{m}^{-2} \mathrm{~s}^{-1}$ and the $\mathrm{CO}_{2}$ concentration injected in the reference chamber set at $400 \mu \mathrm{mol} \mathrm{mol}^{-1}$. On the same days, the chlorophyll content index was measured in three mature fully expanded leaves from each seedling using a Chlorophyll Content Meter CCM-200 (Opti-Sciences, Inc., Hudson, NH, USA).

The stem growth was estimated as the relative stem increment (RSI), in percentage per day. RSI was calculated as the ratio of the stem length growth during the 20 days of waterlogging (corresponding to the height of the second growth flush) and the initial height of the plant (corresponding to the height of the first growth flush).

\subsection{Statistical analysis}

The statistical analyses were performed using R 2.15.0 software (R Development Core Team 2012). The results were considered significant when $p<0.05$. The data represent the mean \pm standard error of the mean.

The significance of the differences between treatments for $A$, gs, and chlorophyll content (waterlogged versus control) was tested using the linear model $\mathrm{Yij}=\mu+\mathrm{Si}+\mathrm{Tj}+\varepsilon \mathrm{ij}$, where Yij is the observed value of the trait, $\mu$ is the overall mean, $\mathrm{Si}$ is the fixed effect of the treatment, $\mathrm{Tj}$ is the fixed effect of the time, and $\varepsilon i \mathrm{ij}$ is the error term. For all variables, postulates of ANOVA were checked. The significance of the differences between the treatments for RSI could not be tested using a linear model because the postulates of the ANOVA were not met; therefore, we performed a Mann-Whitney $U$-test.

To test differences between the control plants and the categories of waterlogged plants that were able or not able to form adventitious roots and hypertrophied lenticels, we created a category $\mathrm{C}$ using the four modalities described. The significance of the difference among the four categories was tested using the linear model $\mathrm{Yij}=\mu+\mathrm{Ci}+\mathrm{Tj}+\varepsilon \mathrm{ij}$, where $\mathrm{Yij}$ is the observed value of the trait, $\mu$ is the overall mean, $\mathrm{Ci}$ is the fixed effect of the category, $\mathrm{T} j$ is the fixed effect of the time, and $\varepsilon i j$ is the error term. These tests were followed by Tukey-Kramer mean comparison tests to investigate pairwise differences of the categories. For all variables, the postulates 
of ANOVA were checked, and to respect homoscedasticity of residuals for gs, this variable was $\log$ transformed.

The significance of the correlations between the RSI and initial assimilation rate was tested using the linear model RSIi $=\mu+A \mathrm{i}+\varepsilon \mathrm{i}$, where RSIi is the observed value of the RSI, $\mu$ is the overall mean, $A \mathrm{i}$ is the fixed effect of the initial assimilation rate, and $\varepsilon \mathrm{i}$ is the error term.

\section{Results}

\subsection{Growth response to water-logging}

Of the waterlogged seedlings, $93 \%$ maintained growth above zero during the experiment. The relative stem increment (RSI) was significantly different for the waterlogged seedlings compared with the controls $\left(2.4 \pm 0.3 \%\right.$ day $^{-1}$ for the waterlogged seedlings, and $3.7 \pm 0.5 \%$ day $^{-1}$ for the control seedlings, Fig. 1). The seedlings subjected to waterlogging that were not able to form morphological adaptations exhibited an RSI three times lower than the controls (Fig. 1). The seedlings with hypertrophied lenticels (including those able or not able to form adventitious roots) exhibited RSIs that were neither significantly different to the controls nor to the seedlings without morphological adaptations.

\subsection{Physiological responses to water-logging}

Net $\mathrm{CO}_{2}$ assimilation rate decreased significantly in response to waterlogging and was $2.3 \pm 0.3 \mu \mathrm{mol} \mathrm{m}^{-2} \mathrm{~s}^{-1}$ on day 20 for the waterlogged seedlings compared with $4.8 \pm$ $0.3 \mu \mathrm{mol} \mathrm{m} \mathrm{m}^{-2} \mathrm{~s}^{-1}$ for the controls (Fig. 2a). The seedlings able to form hypertrophied lenticels and adventitious roots maintained a higher $A$ than the seedlings that did not form

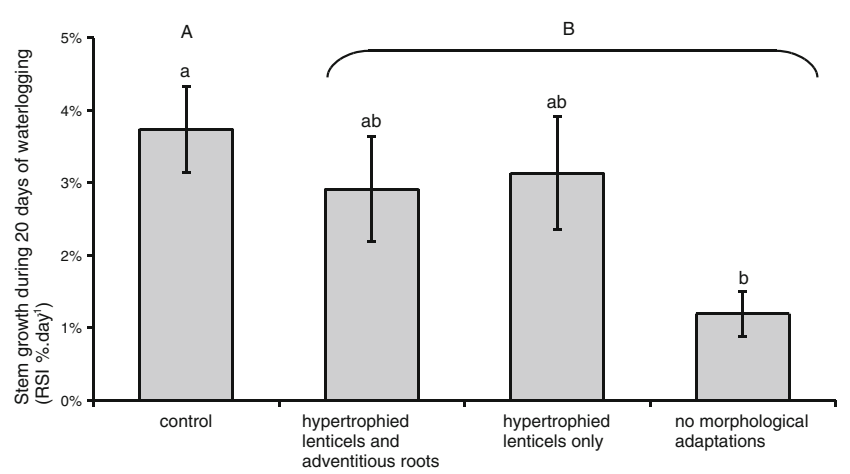

Fig. 1 Stem growth (relative stem increment-RSI) in response to waterlogging and as a function of the capacity to form morphological adaptation. Different lower case letters indicate significant differences among the four categories of seedlings (linear models followed by Tukey-Kramer means comparison test, see Section 2 for details); the different upper-case letters indicate a significant difference between the control and waterlogged seedlings (Mann-Whitney $U$-test, see Section 2 for details). The data represent the mean \pm standard error of the mean morphological adaptations in response to waterlogging (Fig. 2a). Indeed, during the last week of waterlogging, $A$ was maintained at $3.9 \pm 0.3 \mu \mathrm{mol} \mathrm{m} \mathrm{s}^{-2}$ on day 13 and $2.7 \pm$ $0.3 \mu \mathrm{mol} \mathrm{m}^{-1} \mathrm{~s}^{-1}$ on day 20 for the plants with adventitious roots and hypertrophied lenticels, whereas in the plants without adaptive structures, $A$ was $2.5 \pm 0.2 \mu \mathrm{mol} \mathrm{m}^{-2} \mathrm{~s}^{-1}$ on day 13 and $2 \pm 0.2 \mu \mathrm{mol} \mathrm{m}^{-2} \mathrm{~s}^{-1}$ on day 20 . The seedlings with hypertrophied lenticels but no adventitious roots maintained values that were neither significantly different to the controls nor to the seedlings without morphological adaptations.

Stomatal conductance (gs) decreased significantly in both the waterlogged and control seedlings during the experiment (Fig. 2b), and the decrease was significantly greater in the waterlogged seedlings than in the controls. The seedlings able to form or not able to form hypertrophied lenticels and/or adventitious roots did not maintain significantly different gs values (Fig. 2b). However, gs of seedlings with adventitious roots was not significantly different from the control seedlings, whereas it was significantly different from the seedlings without adventitious roots.

The leaf chlorophyll content (chl) increased during the first two weeks for both the control and waterlogged seedlings and was stable starting on day 7 (Fig. 2c). Chlorophyll content reached a significantly lower level (approximately 2/3) in the waterlogged seedlings than in the control seedlings at the end of the waterlogging period. Then, leaf mass area index (LMA) recorded at the end of the experiment did not differ significantly between the waterlogged and control seedlings (164 \pm $3 \mathrm{~g} \mathrm{~m}^{-2}$ for the waterlogged seedlings and $172 \pm 3 \mathrm{~g} \mathrm{~m}^{-2}$ for the control seedlings). Therefore, the LMA did not explain the differences in chl. The seedlings able to form hypertrophied lenticels and adventitious roots maintained a higher chl than the seedlings that did not form morphological adaptations in response to waterlogging (Fig. 2c). The seedlings with hypertrophied lenticels but no adventitious roots maintained values that were neither significantly different to the controls nor to the seedlings without morphological adaptations.

\subsection{Relationships among growth, morphological acclimatisation and initial assimilation rate}

The initial carbon assimilation rate (i.e., the rate recorded on the day preceding the beginning of the stress) explained $31 \%$ of the variability in the RSI during the experiment (Fig. 3). Interestingly, the seedlings with a similar initial assimilation rate to that of the control maintained a similar RSI to the control regardless of the effect of the stress on photosynthesis.

The seedlings that were able or not able to form hypertrophied lenticels and/or adventitious roots exhibited a significantly different initial assimilation rate (Fig. 2a, left part). We classified the seedlings with respect to their initial assimilation rate as follows: seedlings with hypertrophied lenticels and adventitious roots $\left(6.0 \pm 0.5 \mu \mathrm{mol} \mathrm{m}{ }^{-2} \mathrm{~s}^{-1}\right) \geq$ 
Fig. 2 Evolution of carbon assimilation rate $A$ (a), stomatal conductance to water vapor $g S$ (b), and chlorophyll content index $C h l(\mathbf{c})$ in response to waterlogging and as a function of the capacity to form morphological adaptations in response to waterlogging. The vertical dotted line indicates the start of the waterlogging (day 0 ). Different lower-case letters indicate significant differences among the four categories of seedlings, before (left) or during (right) the water-logging. Different upper-case letters indicate significant differences between the control and waterlogged seedlings (linear models followed by TukeyKramer means comparison test, see Section 2 for details). In all cases, the global time effect was significant $(p<0.001)$. The data represent the mean \pm standard error of the mean

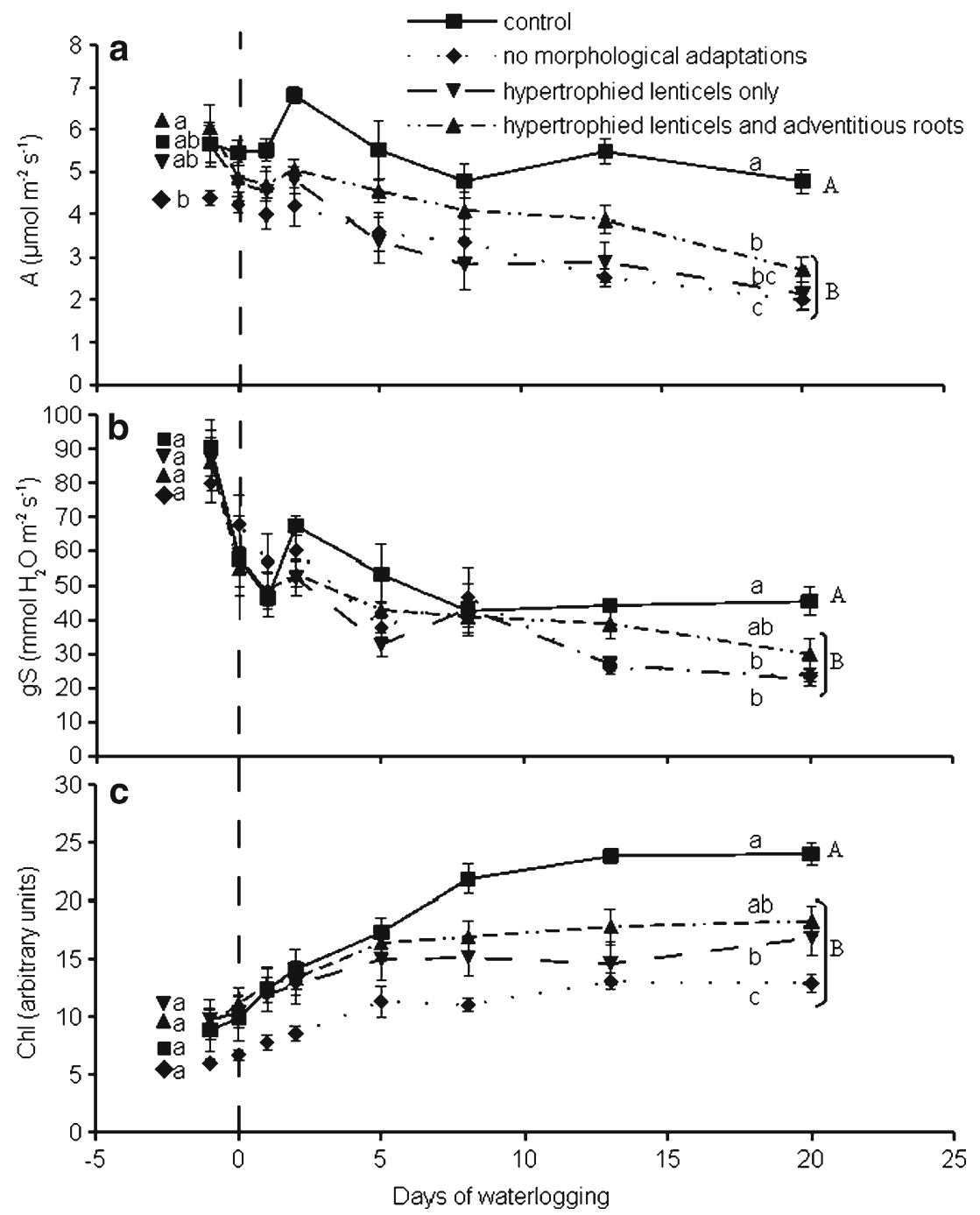

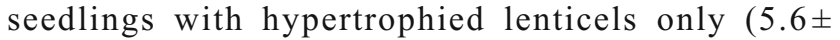
$0.5 \mu \mathrm{mol} \mathrm{m} \mathrm{m}^{-2} \mathrm{~s}^{-1}$, similar to the control) $\geq$ seedlings without these morphological adaptations $\left(4.4 \pm 0.2 \mu \mathrm{mol} \mathrm{m}^{-2} \mathrm{~s}^{-1}\right)$. We

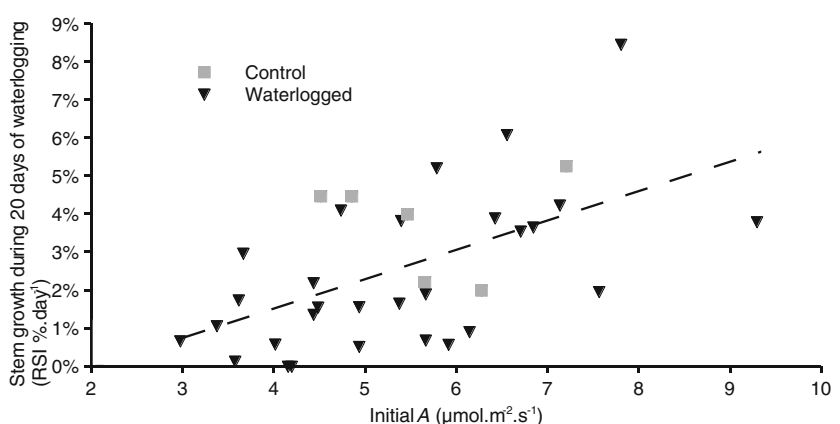

Fig. 3 Correlation between the stem growth (relative stem increment, RSI) and the initial assimilation rate (initial $A$ ). $A$ was recorded the day preceding the beginning of waterlogging. The relative stem increment is the ratio of the growth during waterlogging (corresponding to the second growth flush) and the initial height of the plant (corresponding to the first growth flush), and is expressed as percentage day ${ }^{-1}$. The linear regression including all of the seedlings (control and waterlogged): $p=0.0005, R^{2}=0.31$ did not observe significant differences among the seedlings able or not able to form hypertrophied lenticels and/or adventitious roots for the initial values of gs and chl (Fig. 2b,c, left part).

\section{Discussion}

4.1 Limitation of photosynthesis and growth by waterlogging

Under our experimental conditions, the waterlogging limited the overall growth of the seedlings. This result is commonly observed in this species (Dreyer 1994; Schmull and Thomas 2000; Kreuzwieser et al. 2004), and has been linked to a reduction in carbon assimilation. Numerous studies of temperate forest tree species, and particularly pedunculate oaks (Dreyer 1994), attribute the reduction to a biochemical limitation, which could be related to a reduction in carbohydrate exportation in the phloem (Ferner et al. 2012). In this study, we observed a decrease in $A$ at the beginning of the waterlogging, which occurred at the same time as the increase 
in Ci (data not shown), which was higher for the waterlogged than for the control seedlings. This event did not appear to be related to stomatal closure, because the control plant also exhibited a reduction in the stomatal aperture. Additionally, we observed that the stressed seedlings exhibited lower chlorophyll content than the controls at the end of the experiment. The chlorophyll deficiency could also be a limiting factor for photosynthesis. The results were consistent with the biochemical limitation of photosynthesis that is commonly observed, although our experiment was not designed to demonstrate this phenomenon.

4.2 Does the formation of hypertrophied lenticels and adventitious roots enhance assimilation rate?

If we assume that the biochemical limitations were because of a problem with phloem unloading deficiency (Ferner et al. 2012) and that the hypertrophied lenticels increased the aeration of the main root, we would expect the hypertrophied lenticels to limit unloading deficiency and to induce a higher assimilation rate. However, Shimamura et al. (2010) observed that while hypertrophied lenticels in soybean are formed under water, they transport oxygen efficiently only when they are above the water-table where oxygen is available. In our experiment, we maintained the water-table at a stable level, whereas under natural conditions, these structures are subjected to water-table fluctuations and could be uncovered.

In parallel, root hydraulic conductance appears reduced by waterlogging because of the death of the roots (Schmull and Thomas 2000). The formation of adventitious roots adapted to oxygen deficiency and their presence in the zone where oxygen is available could counteract this problem. Indeed, a number of studies have demonstrated that stomatal reopening during waterlogging co-occurs with the development of adventitious roots on Populus clones (Du et al. 2008) and on Calophyllum brasilense (de Oliveira and Joly 2010).

In this study, we investigated whether the formation of hypertrophied lenticels and adventitious roots had a positive effect on photosynthesis in $Q$. robur seedlings. The results demonstrated that the photosynthesis parameters and growth under the four different conditions were similarly ranking. Indeed, the ranking of the seedlings was as follows: control $\geq$ plants with hypertrophied lenticels and adventitious roots $\geq$ plants with hypertrophied lenticels only $\geq$ plants with no morphological adaptation.

These results suggested that the formation of adventitious roots and hypertrophied lenticels should have enhanced photosynthesis under our experimental conditions. We observed an effect of hypertrophied lenticels alone versus plants with no morphological adaptation. Adventitious roots had an additional effect to this hypertrophied lenticels effect on the carbon assimilation rate. This additive effect was not confirmed by the RSI data.
The stomatal conductance was apparently influenced by the formation of adventitious roots and not by the formation of hypertrophied lenticels, which is in accordance with the potential effect on the root conductance.

\subsection{Does the initial assimilation capacity determine} the formation of morphological adaptations?

We demonstrated that the RSI during waterlogging correlated with the initial assimilation rate. Therefore, the observed effect of morphological adaptation on the assimilation rate could have been a trophic effect; a plant with a high assimilation rate could be more capable of forming morphological adaptations than a plant with a low assimilation rate.

Similar ranking can be done based on initial or final carbon assimilation rate, that is: plants with hypertrophied lenticels and adventitious roots $\geq$ plants with hypertrophied lenticels only $\geq$ plants with no morphological adaptation. The plants with no morphological adaptation exhibited a clearly lower initial assimilation rate than the plants that accumulated adventitious roots and hypertrophied lenticels. The difference between the assimilation rates of the plants with only hypertrophied lenticels and the plants with no morphological adaptations was more pronounced than the difference in the assimilation rates between the plants with adventitious roots and hypertrophied lenticels and the plants with only hypertrophied lenticels. Therefore, the initial assimilation rate appeared to affect the development of hypertrophied lenticels, but not of obviously adventitious roots.

\subsection{Conclusion}

In this study, we investigated the cause-effect relationship between assimilation rate and the development of adaptive structures, aiming at elucidating whether the ability to maintain a high assimilation rate was due to the capacity to form such structures, or if it is photosynthesis capacity which determines the capacity to form those structures. Finally, the two hypotheses were validated by our main results: (1) in our study, the seedlings able to form adventitious roots and/or hypertrophied lenticels were able to maintain a higher assimilation rate during waterlogging. Additionally, we observed the potential effect of adventitious roots on stomatal aperture, and the plants with no morphological adaptations exhibited the lowest growth, and (2) the individual capacity to form hypertrophied lenticels and/or adventitious root and to maintain growth during waterlogging appeared to be determined by the initial carbon assimilation capacity. However, it was difficult to discriminate whether this was the case for the two types of structures; quantitatively, we observed a more pronounced effect of the initial assimilation rate on hypertrophied lenticels than on adventitious roots. In addition, the relative stem 
increment during the waterlogging was correlated with the initial assimilation rate.

Therefore, under our experimental conditions, we demonstrated a two-way cause-effect relationship between the assimilation rate and the formation of hypertrophied lenticels and adventitious roots. Further experiments will be required to investigate the role that the available carbohydrate reserves play in the capacity to form morphological adaptations, which could play a major role in early spring waterlogging when the leaves are not developed.

Acknowledgments We are grateful to the anonymous reviewers of the manuscript for their helpful comments.

Funding This work was supported by the University of Franche-Comté and the regional council of Franche-Comté.

\section{References}

Calvo-Polanco M, Señorans J, Zwiazek JJ (2012) Role of adventitious roots in water relations of tamarack (Larix laricina) seedlings exposed to flooding. BMC Plant Biol 12:99-108. doi:10.1186/14712229-12-99

Copolovici L, Niinemets U (2010) Flooding induced emissions of volatile signaling compounds in three tree species with differing waterlogging tolerance. Plant Cell Environ 33:1582-1594. doi:10. $1111 / j .1365-3040.2010 .02166 . x$

de Oliveira V, Joly C (2010) Flooding tolerance of Calophyllum brasiliense Camb. (Clusiaceae): morphological, physiological and growth responses. Trees Struct Funct 24:185-193. doi:10.1007/ s00468-009-0392-2

Dittert K, Wotzel J, Sattelmacher B (2006) Responses of Alnus glutinosa to anaerobic conditions - mechanisms and rate of oxygen flux into the roots. Plant Biol 8:212-223. doi:10.1055/s-2005-873041

Dreyer E (1994) Compared sensitivity of seedlings from 3 woody species (Quercus robur L., Quercus rubra L., and Fagus sylvatica L.) to water-logging and associated root hypoxia: effects on water relations and photosynthesis. Ann For Sci 51:417-429. doi:10.1051/ forest: 19940407

Du KB, Shen BX, Xu L, Tu BK (2008) Estimation of genetic variances in flood tolerance of poplar and selection of resistant F1 generations. Agrofor Syst 74:243-257. doi:10.1007/s10457-008-9112-y

Ferner E, Renneberg H, Kreuzwieser J (2012) Effect of flooding on C metabolism of flood-tolerant (Quercus robur) and non-tolerant (Fagus sylvatica) tree species. Tree Physiol 32:135-145. doi:10. 1093/treephys/tps009

Folzer H, Dat JF, Capelli N, Rieffel D, Badot PM (2006) Response of sessile oak seedlings (Quercus petraea) to flooding: an integrated study. Tree Physiol 26:759-766. doi:10.1093/treephys/26.6.759

Gravatt DA, Kirby CJ (1998) Patterns of photosynthesis and starch allocation in seedlings of four bottomland hardwood tree species subjected to flooding. Tree Physiol 18:411-417. doi:10.1093/ treephys/18.6.411

Kozlowski TT (1997) Responses of woody plants to flooding and salinity. Tree Physiol Monogr 1:1-29

Kreuzwieser J, Papadopoulou E, Rennenberg H (2004) Interaction of flooding with carbon metabolism of forest trees. Plant Biol 6:299306. doi:10.1055/s-2004-817882

Larson D, Davies FS, Schaffer B (1991) Floodwater temperature and stem lenticel hypertrophy in Mangifera indica (Anacardiaceae). Am J Bot 78:1397-1403. doi:10.2307/2445278

Lévy G, Lefèvre Y, Becker M, Frochot LH, Picard JF, Wagner PA (1999) Excess water: effects on growth of the oak tree. Rev For Fr 51:151161. doi:10.4267/2042/5427

Mielke MS, De Almeida AAF, Gomes FP, Aguilar MAG, Mangabeira PAO (2003) Leaf gas exchange, chlorophyll fluorescence and growth responses of Genipa americana seedlings to soil flooding. Environ Exp Bot 50:221-231. doi:10. 1007/s11738-010-0702-8

Parelle J, Brendel O, Bodenes C, Berveiller D, Dizengremel P, Jolivet Y, Dreyer E (2006) Differences in morphological and physiological responses to water-logging between two sympatric oak species (Quercus petraea [Matt.] Liebl., Quercus robur L.). Ann For Sci 63:849-859. doi:10.1051/forest:2006068

Parelle J, Brendel O, Jolivet Y, Dreyer E (2007) Intra and inter-specific diversity of the response to water-logging in two co-occuring white oak species (Quercus robur and Q. petraea). Tree Physiol 27:10271034. doi:10.1093/treephys/27.7.1027

Parent C, Crèvecoeur M, Capelli N, Dat JF (2011) Contrasting and adaptive responses of two oak species to flooding stress: role of non-synbiotic haemoglobin. Plant Cell Environ 34:1113-1126. doi: 10.1111/j.1365-3040.2011.02309.x

Pezeshki SR, Pardue JH, DeLaune RD (1996) Leaf gas exchange and growth of flood-tolerant and flood-sensitive tree species under low soil redox conditions. Tree Physiol 16:453-458. doi:10.1093/ treephys/16.4.453

R Development Core Team (2012) R: a language and environment for statistical computing. Foundation for Statistical Computing, Vienna (http://www.R-project.org)

Schmull M, Thomas FM (2000) Morphological and physiological reactions of young deciduous trees (Quercus robur L., Q. petraea [Matt.] Liebl., Fagus sylvatica L.) to waterlogging. Plant Soil 225: 227-242. doi:10.1023/A:1026516027096

Sena Gomes AR, Kozlowski TT (1980) Growth responses and adaptations of Fraxinus pennsylvanica seedlings to flooding. Plant Physiol 66:267-271. doi:10.1104/pp. 66.2.267

Shimamura S, Yamamoto R, Nakamura T, Shimada S, Komatsu S (2010) Stem hypertrophic lenticels and secondary aerenchyma enable oxygen transport to roots of soybean in flooded soil. Ann Bot 106:277284. doi:10.1093/aob/mcq123

Tang ZC, Kozlowski TT (1984) Water relations, ethylene production, and morphological adaptation of Fraxinus pennsylvanica seedlings to flooding. Plant Soil 77:183-192. doi:10.1007/BF02182922

Wagner P, Dreyer E (1997) Interactive effects of waterlogging and irradiance on the photosynthetic performance of seedlings from three oak species displaying different sensitivities (Quercus robur, Q. petraea and Q. rubra). Ann Sci For 54:409-429. doi:10.1051/ forest:19970501 